\title{
A presidência e a separação dos poderes no Brasil (1999-2002**
}

\author{
Kurtvon Mettenheim
}

\author{
0 Presidente não é a Presidência. \\ A Presidência não é $0 \mathrm{G}$ overno. \\ 0 nosso sistema não é presidencial. \\ Char Les 0 . Jones, T he Presidency in a separated system.
}

\section{Introdução}

A epígrafe que abre este texto serve de alerta contra o fetichismo comum à pessoa presidencial, e também para que se atente à confusão conceitual sobre o presidencialismo. Com isso queremos enfatizar a importância da separação dos poderes no sistema político brasileiro. 0 ptamos por essa perspectiva teórica "separacionista" a fim de evitar os vieses do eurocentrismo e do reformismo liberal que permeiam boa parte dos estudos das instituições políticas brasileiras, especialmente no que se refere a debates que opõem formas de governo numa falsa dicotomia entre presidencialismo e parlamentarismo ${ }^{1}$. Pouco tempo se passou após o fim de um mandato presidencial para que possamos fazer uma análise política mais abrangente e objetiva do tema; portanto, o que propomos aqui é um balanço ainda inicial da segunda gestão FH C (1999-2002), no sentido de enfatizar a separação cada vez maior dos poderes durante esse período e de refletir sobre o contexto mais amplo de mudanças políticas, sociais e econômicas que estão definindo a democracia brasileira.
*A gradeço os comentáriose sugestõesa versões anteriores deste trabalho apresentado nas reuniões da Associação N acional dePós Graduação e Pesquisa em C iências Sociaise daAssociação Brasileira de C iência Política, como também o apoio financeiro do $\mathrm{N}$ úcleo de Pesquisas e Publicações daEaesp-FGV.

1. Sobre as distorções do eurocentrismo e do reformismo liberal, ver 0 'D onnell (1996, pp. 34-51). 
2. T sibelis (1997) sustenta que a diferença fundamental entre as formas de governo está no número de pontos de veto. $\mathrm{N}$ ossa análise sugere que os pontos podem também ser de iniciativa e acesso, ou seja, a separação de poder na democracia é mais soma positiva.

3.O bservam Dahl e Lindblom: "a intenção evidente da C onvenção $\mathrm{N}$ acional era a de que não houvesse nos Es tadosU nidosrepresentantes unificados, coesos, reconhecidos e legítimosda'maioriana cional'. Com freqüência, o presidente sustenta representar uma maioria nacional e o Congresso (ou uma maioria das duas ( asas), outra.A convenção foi tão bem-sucedida que até quando uma maioriano Congresso pertencenominalmente ao mesmo partido que o presidente, este e aquela não costumam falar com a mesma voz" (1956, pp. 335-336).
Essa perspectiva separacionista capta e valoriza o fato de que as análises das instituições políticas brasileiras desde 1988, em conjunto, apresentam um volume importante de evidências de empowerment em todos os três ramos do governo federal - Executivo, Legislativo e Judiciário. Esse processo de empowerment simultâneo é aparentemente paradoxal para aquelas teorias que retratam o poder institucional e o governo em termos de soma zero ${ }^{2}$. C ontrariamente a essas teorias, nosso argumento é de que a crescente separação dos poderes desde 1988, longe de reduzir o poder presidencial, acabou gerando um processo político federal mais complexo, que tende a envolver os três poderes de diversas maneiras, tanto formais como informais, como também outros níveis de governo e atores sociais. A sinstituições políticas brasileiras e norte-americanas diferem bastante, especialmente pela predominância maior do Executivo brasileiro. Porém, apesar dessas diferenças, conceitos sobre política nos Estados U nidos, como o de governo dividido e o de separação de poderes, proporcionam uma perspectiva nova para começarmosa analisar o que ocorreu durante o segundo mandato de FHC.

Essa perspectiva separacionista tem origem na tradição pluralista norte-americana de pesquisar as interações entre os poderes, em vez de contrapor um ramo ou nível de governo aos demais. A ssim, pesquisas sobre a presidência norte-americana tendem a dar ênfase à negociação, às trocas de interesses e favores, e aos padrões de colaboração e conflito, como chaves importantes para o sucesso no relacionamento com os outros poderes. G reenstein (1982), por exemplo, alude ao conceito de hidden hand, não para afirmar as virtudes dos mercados, mas para capturar o caráter minimalista da presidência nos Estados U nidos. 0 utro clássico, Presidential power, de N eustadt (1960), também descreve as instituições políticas dos Estados U nidos como "instituições separadas que compartilham poderes" e define a persuasão, a barganha e as trocas como as características responsáveis pelo sucesso ou fracasso dos presidentes, em uma perspectiva que aponta claramente para o chão teórico pluralista que insiste na difusão de poder. O utrostrabalhos como D ivided we govern, de M athew (1989), e T he presidency in a separated system, de Jones (1994), sugerem que, ao contrário dos que enfatizam riscos de governabilidade supostamente associados ao presidencialismo, a separação de poderesfoi concebida- e continua sendo como um arcabouço institucional que visa a produzir conflito permanente entre princípios contrastantes de representação. A ssim chegamos ao cerne da dinâmica mais relevantes para os governos e as presi dências eficazes 3 . 
Esta análise também dá ouvidos ao alerta de O 'D onnell (1996) a respeito de se evitar as distorções do reformismo liberal e do eurocentrismo nas análises de instituições políticas em contextos de pós transição de regimes autoritários. Esse autor adverte que conceitos e teorias idealizadas de poliarquias antigas não são boas referências para a análise dos processos políticos pós-transição no Sul e no O riente mundial. Sob esse aspecto, acreditamos que há notáveis semelhanças de viés liberal reformista entre os programas de reforma do passado e do presente. As propostas de reforma da A merican Political Science A ssociation (APSA), de $1950^{4}$, nos surpreendem pela semelhança que apresentam com as agendas de reforma política bastante debatidas no B rasil recentemente. Esses vieses nos parecem exemplos das ilusões so bre a consolidação da democracia, no sentido de que ambas as pautas de reforma, mas de cinqüenta anos atrás nos Estados U nidos e hoje no Brasil, envolvem propostas de mudanças radicais nas regras institucionais, visando, erroneamente, à agilização do processo político e governamental. Em geral, reformas políticas procuram concentrar o poder e diminuir o debate e a contestação, ou seja, reduzem a separação de poderes na tentativa frustrada de aumentar a responsabilidade dos partidos ou a governabilidade.

A perspectiva separacionista também difere de percepções jurídicas ou funcionais que procuram demarcar o Executivo, o Legislativo e o Judiciá rio numa seqüência linear (também idealizada) da representação política, em que as leis, em princípio, refletiriam mais fielmente somas e maiorias entre as preferências dos eleitores. 0 pondo-se a essa visão tradicional de que o Legislativo legisla, o Executivo executa e o Judiciário julga, trabaIhos empíricos sugerem que a formulação, a apresentação, 0 debate, a aprovação, a implementação, a contestação e a revisão constitucional de leis circunscrevem-se em uma longa série de momentos de resolução de conflitos e tentativas de conciliação, envolvendo quase permanentemente a presidência, o congresso e os tribunais, além de cargos executivos, burocracias, grupos de interesses e organizações não-governamentais. $N$ a perspectiva separacionista, a presidência encontra-se no interior desse processo pluralista, gradualista, e eivado de interferência, uma perspectiva que difere profundamente da estratégia de reformar as instituições políticas e aumentar a governabilidade por meio da agilização da política e da centralização do poder ${ }^{5}$.

Antes de considerarmos a presidência e a separação de poderes de 1999 a 2002, oferecemos brevemente um olhar histórico sobre a presi-
4.0 painel daAPSA, que em 2000 celebrou o 50aniversário do relatório do Comitê de Partidos Políticos analisou diversos acontecimentosocorridosna segunda metade do sé culo XX, como atelevisão, a consultoria de campanhae a queda do partidarismo entre os eleitores representantes, o que, aparte das questões de eurocentrismo e reformismo liberal enfatizadosaqui, também exigem uma reavaliação das teorias sobre partidos responsáveis e sistemas partidários.

5. N esse sentido, parece-nos peculiar que muddling through seja uma das grandes virtudes da política pluralistadosEstadosU nidos, enquanto o jeito permanece como um dos grandes vícios da políticabrasileirase, afinal, são tão parecidos (cf. Lindblom, 1968). 
dência da R epública; abordamos as eleições presidenciais desde 1989 para pôr em relevo a importância de eleições críticas e do realinhamento eleitoral, como também supercoalizões entre partidos no sistema partidário e eleitoral brasileiro. $M$ ais adiante, passamos a comentar a segunda gestão FHC, enfatizando o conteúdo heterodoxo das reformas tucanas, assim como o papel da presidência na política econômica e social e na política exterior. Por todo o texto, há duas preocupações: 1) examinar a separação de poderes entre as instituições políticas brasileiras; e 2) inserir a presidência da R epública num contexto mais amplo das mudanças sociais e econômicas que ocorreram no Brasil nesse período.

\section{Pesquisas recentes sobre a separação de poderes no Brasil}

Sugerimos que as pesquisas sobre as instituições políticas brasileiras desde a Constituição federal de 1988 apontam uma importância cada vez maior de cada ramo do governo federal (cf. Palermo, 2000). Para uns como Vianna et al. (1999), Sadek (1999), A rantes (1997) e C astro (1997), houve uma judicaliz ação da política no período recente, pois os tribunais brasileiros aumentaram sua participação na formulação de políticas e na tomada de decisões. D a mesma forma, análises so bre o C ongresso e o Sena do propõem que o Legislativo brasileiro tenha aumentado sua influência sobre o processo político, apesar da predominância tradicional do Executivo (A morim N eto e Santos, 2001).

$N$ esse sentido, é importante notar que mudanças nas regras entre poderes e as emendas constitucionais aprovadas em 2001 e 2002 reduziram

6.Sobre a dinâmica entre o Executivo e 0 Legislativo na negocia ção de decretos no Brasil e na Argentina, verVasconcelos (2001). dramaticamente os poderes de decreto da presidência brasileira ${ }^{6}$. 0 Senado aprovou (em 6 de setembro de 2002) uma emenda constitucional que limita a vigência das medidas provisórias a dois períodos de sessenta dias. A decisão do Senado (66 votos a favor, três contra e uma abstinência) refletiu o mesmo acordo amplo entre o governo e a oposição, que preva lecera em junho de 2002, quando os deputados federais votaram por 417 a um pelo fim da reedição de medidas provisórias. Tendo em vista a exigência de apreciar as medidas provisórias antes da legislação ordinária e votá-las dentro de 45 dias, essas mudanças trouxeram o Congresso mais para o centro dos debates sobre diretrizes políticas. 0 utro aspecto que exige mais cooperação entre oposição e governo é o bloqueio da agenda do C ongresso até que ambas as casas votem as medidas provisórias editadas pela presidência. Essa regra desafia governo e a oposição a coopera- 
rem, a fim de evitar problemas de governabilidade, pois importantes temas legislativos estão impossibilitados de chegar aos plenários legislativos enquanto tais medidas não forem votadas.

A ssim, o rompimento do Partido da Frente Liberal (PFL) com o Partido da Social Democracia Brasileira (PSDB), em 2001, parecia provocar um engarrafamento legislativo. C omo o C ongresso não aprovou a prorrogação da C ontribuição Provisória sobre M ovimentação ou Transmissão deValores e de $C$ réditos e de $D$ ireitos de $N$ atureza Financeira (CPM F), as novas regras proibiam o C ongresso de votar outras leis em pauta antes de votar as medidas provisórias relevantes. Em curto prazo, essas mudanças pareciam aumentar o poder de veto do PFL nas posições de liderança no Legislativo. $\mathrm{N}$ o entanto, essa estratégia de veto do PFL começou a prejudicar a imagem do partido, uma vez que o custo do atraso na votação da CPM F foi estimado em $R \$ 400$ milhões por semana durante boa parte do segundo trimestre de 2001.

0 uso anterior das medidas provisórias também não deve obscurecer o fato de que a maior parte da legislação brasileira passa por um processo longo e complexo de votações duplas num sistema bicameral. D e acordo com a Constituição federal de 1988, a aprovação de legislação - seja ordinária ou complementar - depende de duas votações nos plenários, tanto no Senado como na $C$ âmara dos $D$ eputados. D e novo, esse processo mais longo não parece reduzir a governabilidade, ao contrário, as votações de grandes blocos de leis por supermai orias legislativas confirmam que um fenômeno central da política brasileira após as eleições é a formação de supercoalizões multiparti dárias para dar sustentação às iniciativas legislativas do Executivo. $D$ ado que o sistema multipartidário tende a impedir a formação de maioria simples no Legislativo, as relações entre os poderes exigem a manutenção de maiorias formadas depois do pleito eleitoral. Tais coalizões governamentais não são baseadas, a priori, em disciplina partidária ou proximidade ideológica. M esmo assim, presidentes brasileiros tendem a obter supermaiorias no Legislativo para garantir a aprovação de leis essenciais.

\section{A supercoalizão do PSDB em 1999-2002}

E mbora uma análise mais aprofundada seja ainda necessária, um exame inicial do período anterior, a partir de 1988, sugere que as pressões geradas por crises econômicas ou outros momentos políticostendem a reforçar as 
coalizões legislativas e a criar períodos concentrados de produtividade legislativa. Durante o primeiro semestre de 1995, o presidente Fernando $\mathrm{H}$ enrique $\mathrm{C}$ ardoso conseguiu aprovar uma série de emendas constitucionais e de leis ordinárias e complementares, todas de grande impacto na vida econômica e social do país. Esses períodos não se limitam à lua- demel que se segue às eleições presidenciais. U ma sessão extraordinária convocada por FH C em fevereiro de 2001 transformou em lei 23 das 75 medidas provisórias, justamente enquanto se desintegrava a coalizão formal entre o PSD B e o PFL, que durou sete dos oito anos de gestão FH C.

Q ual a lógica dessas supercoalizões? A análise empírica há muito confirmou a importância das nomeações políticas em sistemas de separação de poderes. D esde as agudas observações feitas por Bryce (1907) eW eber (1946) sobre as indicações presidenciais para cargos executivos, os estudiosos reconhecem que a prerrogativa de que gozam os presidentes para distribuir postos entre seus aliados é, em grande parte, responsável pela singular trajetória do desenvolvimento político nos Estados U nidos. Embora as reformas do funcionalismo público norte-americano nas décadas de 1910, 1970 e 1990 tenham reduzido o número de indicações políticas para cargos administrativos, as nomeações nos sistemas presidenciais são claramente diferentes da autonomia das burocracias e dos quadros executivos de primeiro escalão dossistemas parlamentares (cf. Schultz e M aranto, 1998; Stewart, 1989; Skowroneck, 1982). A rnold (1979) demonstra que uma mudança de administração envolvia aproximadamente 150 nomeações na G rã-B retanha (nos anos de 1960) contra cerca de dez mil distribuídas pelos presidentes dos Estados U nidos. D esde os estudos de A rnold, uma série mais recente sobre três importantes reformas realizadas nos Estados U nidos sugeriu que os presidentes desse país não nomeassem mais do que três mil pessoas para cargos executivos (D olan, 2000).

N omeações também movem a política entre os poderes no Brasil. A morim e Santos (2001) analisaram dados de períodos anteriores da democracia brasileira (após o fim do regime militar) que revelaram números extremamente altos. É bom lembrar queTancredo $\mathrm{N}$ eves e outros construíram a aliança democrática entre o Partido do M ovimento D emocrático Brasileiro (PM D B) e dissidências do PFL sobre uma lista gigantesca de nomeações (em torno de $140 \mathrm{mil}$ ). D esde a Constituição federal de 1988 e as reformas tucanas na administração federal, o número geral de servidores federais, como também o número de nomeações políticas para cargos executivos, caíram substancialmente. 0 número total de servidores 
públicos federais caiu de cerca de 720 mil, em 1995, para cerca de 490 mil, em 2003, enquanto o número de cargos políticos caiu de cerca de 73 mil, em 1995, para cerca de 23 mil, em 2003.

A lógica dessas nomeações molda- se à formação do governo de coalizão no sistema de separação de poderes do Brasil, visando à sustentação das coalizões governistas no Legislativo. No caso da aliança PSD B-PFL que apoiou o presidente FH C e suas reformas de 1995 a 2001 (apesar de essa aliança ser desfeita em março de 2002, com a saída dos pefelistas), a administração foi capaz de garantir votações com uma seqüência de supermaiorias típicas das supercoalizões do governo federal brasileiro (Tabela 1).

TABELA 1

SupercoalizãoTucana no L egislativo (2001)

\begin{tabular}{|c|c|c|c|c|c|c|c|}
\hline \multicolumn{4}{|c|}{ Câmara dos Deputados } & \multicolumn{4}{|c|}{ Senado } \\
\hline \multicolumn{2}{|c|}{ Coalizão Tucana } & \multicolumn{2}{|c|}{ O POSIÇÃO } & \multicolumn{2}{|c|}{ CoAlizÃo TuCANa } & \multicolumn{2}{|c|}{ O POSIÇÃO } \\
\hline PSD B & 92 & PT & 60 & PSD B & 13 & PT & 7 \\
\hline PFL & 95 & PM DB & 30 & PFL & 16 & PM DB & 8 \\
\hline PM DB & 61 & PTB & 32 & PM DB & 18 & PT B & 3 \\
\hline PPB & 51 & $\mathrm{PL}$ & 23 & PPB & 2 & PL & 2 \\
\hline PTB & 16 & PPS & 13 & PTB & 3 & PPS & 1 \\
\hline PDT & 17 & PDT & 4 & & & & \\
\hline TOTAL & 315 & & 165 & & 52 & & 25 \\
\hline
\end{tabular}

O bs: PM D B - estimativa para 2001 a partir do cisma ocorrido na convenção partidária de junho de 2002 entre grupos que apoiavam a aliança PSD B-PM D B e outros que se alinhavam com a oposição.

Em suma, a supercoalizão tucana que deu sustentação ao governo foi produto de uma série de alianças e negociações oscilantes dentro de circunstâncias mutáveis. Por exemplo, apesar de preocupações generalizadas quanto à governabilidade após a saída do PFL da coalizão governista, a prorrogação daCPM F paraalém de 18 de junho de 2002, essencial para os propósitos do governo, foi aprovada nas duas $C$ asas. A votação deu-se porque o presidente $\mathrm{FHC}$ suspendeu a liberação de $\mathrm{R} \$ 5,3$ bilhões do orçamento de 2002 para cobrir perdas de receita que adviriam da não confirmação da C PM F. Embora o PFL continuasse a resistir, apóso R eal cair 10\% em relação ao dólar e o risco-Brasil explodir, o C ongresso aprovou a prorrogação desse tributo em 12 de junho. Em suma, os mecanismos de sus- 
tentação de supercoalizões no governo federal brasileiro diferem da rigidez das coalizões permanentes negociadas em sistemas parlamentaristas.

\section{A presidência na história brasileira}

$\mathrm{N}$ a ausência de estudos históricos institucionais mais desenvolvidos sobre a presidência brasileira (cf. Silva, 1989), apresentamos aqui um breve olhar histórico na tentativa de contextualizar esse processo mais recente de separação dos poderes. Esse olhar, para os clássicos da ciência política brasileira, assim como alguns dados empíricossugerem que supercoalizões prevalecem nos períodosanteriores à democracia brasileira. Pessanha (1997) sustenta que a C onstituição federal de 1988 difere consideravelmente das constituições brasileiras anteriores no tocante às relações entre Executivo e Legislativo (cf. Figueiredo e Limongi, 2001). A o contrário dos sistemas anteriores, que privilegiavam o Congresso (1946-1964) ou o Executivo (1967-1988), a Constituição de 1988, de acordo com Pessanha, "inova por estabelecer um equilíbrio entre os três poderes do governo, além de estabelecer um poderoso M inistério Público" (1997, p. 92). Além de diversas relações entre os três ramos do governo, Pessanha enfatiza o novo papel do Tribunal de C ontas da U nião (TCU ) e a independência adquirida pelo M inistério Público, que migrou do Executivo para o Judiciário, considerando fundamentais essas mudanças advindas da Constituição de 1988.

O utros trabalhos sobre as instituições políticas brasileiras também já mostraram a importância das relações entre Executivo e Legislativo ao longo da história. Souza (1976) afirma que a predominância do Executivo nas questões centrais de política econômica entre 1930 e 1964 é uma das principais causas dos vícios democráticos e da irresponsabilidade legislativa no período. 0 colapso da democracia e a intervenção militar criaram um processo político excludente entre 1964 e 1985, com o poder centrado

7. Sobre a descrição de círculos concêntricos de influência no regime militar, ver $\mathrm{C}$ ardoso (1975). na presidência e seus superministérios ${ }^{7}$. 0 longo caminho entre 1974 e 1985, de distensão, abertura e liberalização, teve 0 efeito de manter esse controle político centralizado na presidência e nos superministérios durante toda a transição brasileira.

M esmo que períodos anteriores fujam do nosso foco, vale a pena fazer uma observação de caráter geral. Parece-nos que o crescimento administrativo da presidência brasileira reflete a inclusão de mais agentes políticos durante períodos críticos de mudança política na história do país. D esde os primórdios da R epública, em 1891, o número de ministérios muda, 
não de forma linear, movido por algum processo de evolução organizacional gradual, mas sim periodicamente e pontualmente, como reação às transformações das mudanças políticas no governo federal brasileiro (Tabela 2). Esse processo é consistente com análises que enfatizam momentos políticos nas trajetórias de mudança institucional (cf. Pierson e Skocpol, 2003) como também com análises da presidência norte-americana sugerindo que as modificações políticas e de regime tendem a ser a melhor explicação para a trajetória de sua evolução administrativa (cf. Skow ronek, 1982; Lowi, 1979).

TABELA 2

$\mathrm{N}$ úmero de $\mathrm{M}$ inistérios por $\mathrm{M}$ andato P residencial (1899-2002)

\begin{tabular}{|c|c|c|c|c|}
\hline 1889-1930 & 1930-1945 & 1945-1964 & 1964- 1985 & $1985-2002$ \\
\hline 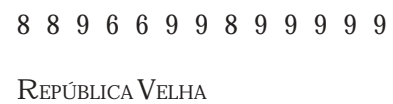 & $\begin{array}{l}131213 \\
\text { ERA VARGAS }\end{array}$ & $\begin{array}{lllllll}16 & 17 & 16 & 17 & 18 & 18 & 19 \\
\text { DEMOCRACIA } & & & \end{array}$ & $\begin{array}{l}19212222222226 \\
\text { Governo M ILITAR }\end{array}$ & $\begin{array}{l}37353137 \\
\text { DEMOCRATIZACCÃO }\end{array}$ \\
\hline
\end{tabular}

F onte: Brasil, Presidência da R epública (1997).

Embora apenas indicativos, esses dados sugerem que o estabelecimento de novos ministérios ocorre logo após mudanças de regime, e não durante períodos de continuidade política. Assim, o executivo brasileiro expandiu- se após três grandes episódios: a revolução de 1930, a intervenção militar de 1964 e a transição do governo militar para o civil em 1985. 0 número, a natureza e o momento dessas inovações organizacionais sugerem a necessidade de uma explicação política. U ma explicação ideológica é adequada no caso da EraVargas (governo provisório e Estado N ovo), pois seus líderes visavam à expansão do número e da função de ministérios e cargos diretamente ligados à presidência. Em termos ideológicos, é muito menos evidente que um aumento substancial de ministérios e órgãos executivos ocorra depois do golpe militar de 1964, dado o caráter excludente da ideologia militar de segurança e desenvolvimento nacionais. Finalmente, 0 aumento do número de postos ministeriais e agências que se reportam diretamente ao presidente, após a transição do governo militar em 1985, confirma que as nomeações ministeriais servem para cimentar novos regimes e coalizões governamentais.

Assim, duas das três principais mudanças de regime na história brasileira pareceriam favorecer a redução das funções administrativas do go- 
verno federal. M as ocorreu o contrário: tanto os presidentes militares do final da década de 1960 como os primeiros presidentes civis após a transição em 1985 aumentaram consideravelmente o número de ministérios. C onclui-se que o uso de nomeações presidenciais para cargos ministeriais e administrativos, durante períodos de mudança política, parece ser de extrema importância para solidificar novos regimes.

\section{Eleição crítica e realinhamento partidário (1994-2002)}

O utros conceitos da ciência política nos EstadosU nidos sobre eleições críticas e realinhamento eleitoral trazem uma nova luz sobre a presidência durante a segunda gestão FH C . N esse sentido, é possível que, no futuro, 0 ano de 1994 seja considerado o de uma eleição crítica no sentido de Key (apud C ummings, 1988) que realinhou as máquinas eleitorais e partidárias brasileiras em alianças amplas, visando apoio e oposição ao governo tucano de coalizão. As teorias de eleições críticas e de realinhamento eleitoral concentram-se em intervalos de tempo maiores do que as três disputas ocorridas desde 1994. M as, ascampanhaspresidenciais de 1994, 1998 e 2002 parecem ter criado uma clivagem eleitoral e partidária, como também a redução da força dos apelos de partidos e candidatos menores. I sso indica, nos termos de Lipset e R okkan (1967) e Sartori (1982), que o congelamento ou a consolidação do sistema partidário brasileiro está em curso, no sentido de construir barreiras de entrada cada vez maiores para partidos menores. A presentamos a seguir al gumas das características emergentes da política partidário- eleitoral brasileira desde a C onstituição de 1988, as quais podem indicar a validade desse argumento quanto a eleições críticas e realinhamento partidário em campanhas presidenciais.

Primeiro, é importante notar que esses processos de eleição crítica e realinhamento partidário têm como motor central o caráter plebiscitário das campanhas presidenciais brasileiras. E, ao contrário das campanhas eleitoraisem democracias antigas, em que candidatose suas equipes focavam seus efforços em alguns pequenos gruposindecisos do eleitorado, no B rasil predominam apelos mais amplos aos eleitores em geral; apelos que são fluidos, porém atrelados a percepções de personalidades políticas e con-

8. Sobre a dinâmica da opinião pública brasileira, ver M ettenheim (1995). cepções subjacentes de justiça substantiva ${ }^{8}$. D o ponto de vista histórico, parece que a tradição populista dotou as relações entre o Executivo e a sociedade no Brasil de maior "transparência" e imediatismo, em comparação aos eleitorados mais rígidos da Europa e dos Estados U nidos (ainda 
que em muitas dessas democracias antigas os cientistas políticos identifiquem tendências em direção a apelos populares diretos por parte dos candidatos).

O utra característica das eleições presidenciais brasileiras é a volatilidade das preferências entre eleitores durante os meses de campanha eleitoral. D esde 1989, os últimos seis meses das campanhas nacionais assistiram a deslocamentos dramáticos nas preferências de voto. $\mathrm{N}$ as primeiras eleições presidenciais, apósa ditadura militar, Fernando Collor começou com uma pequena porcentagem de preferência entre eleitores e acabou por derrotar o candidato do PT, Luiz I nácio Lula da Silva, por uma diferença de mais de $8 \%$ no segundo turno. Em 1994, o então ministro da Fazenda, Fernando $\mathrm{H}$ enrique $\mathrm{C}$ ardoso, passou de $7 \%$ nas pesquisas de abril para mais de $54 \%$ na eleição, derrotando o candidato petista no primeiro turno. Em 1998, o presidente FH C passou de $36 \%$ em abril para mais de $53 \%$ ao final do primeiro turno, novamente derrotando Lula. Em suma, a velocidade e a amplitude de mudanças nas intenções de voto no Brasil são consideravelmente maiores do que as variações entre 3\% e 5\% que tradicionalmente ocorrem durante as campanhas eleitorais nacionais européias e norte-americanas.

É também importante notar que um princípio central existente na fórmula de representação eleitoral brasileira é justamente o de contrabalançar essas tendências plebiscitárias das eleições diretas para o Executivo, por meio da combinação de eleições em separado dos legisladores, com a aplicação de regras bastante liberais de representação proporcional. Esse tipo de combinação vem sendo mantido no Brasil desde o Código Eleitoral de 1932, inspirado por Assis Brasil.

$\mathrm{N}$ esse sentido, o pleito presidencial de 1989 deu-se à margem das tradições brasileiras por ter ocorrido "descasado" do pleito proporcional para o Legislativo, assim como as disputas pelos governos estaduais. Fernando Collor de M ello (PR N) pôde, dessa forma, dominar os primeiros seis meses da campanha, por meio de aparições na televisão e de denúncias de corrupção contra o governo Sarney. D epois de atingir mais de $45 \%$ das intenções de voto em junho, Collor recusou-se a participar dos debates para o primeiro turno, obtendo neste mais de $28 \%$ dos votos, enquanto o segundo colocado, Luiz Inácio Lula da Silva (PT), obteve $16 \%$. Embora Lula tenha dominado o primeiro debate televisivo do segundo turno e arrancado nas pesquisas, empatando com Collor meros dez dias antes da eleição de 15 de dezembro, o candidato petista patinou
9. Sobre estabilidade e mudança eleitorais na Europa, ver Bartolini e M air (1990). 
no segundo debate e não foi capaz de reverter os danos causados pela publicidade negativa feita nos últimos dias da campanha. Collor convenceu os eleitores de que uma vitória do PT desestabilizaria a sociedade e faria com que o Brasil voltasse as costas a um mundo em processo de liberalização, lançando uma série de ataques pessoais e políticos sete dias antes do dia de votação. Em 15 de dezembro, Collor obteve 35.089.998 votos $(42,7 \%)$, contra 31.076 .364 votos $(37,8 \%)$ de Lula.

TABELA 3

E leições P residenciais de 1994

\begin{tabular}{|c|c|c|c|}
\hline Partido & Candidato & Votos & \%VOTOSVÁLIdOS \\
\hline PSD B & Fernando H. Cardoso & 34.364 .961 & 54,27 \\
\hline PT & Luiz Inácio da Silva & 17.122 .127 & 27,04 \\
\hline PRONA & Enéas $C$ arneiro & 4.671 .457 & 7,38 \\
\hline PMDB & $O$ restes $Q$ uércia & 2.772 .121 & 4,38 \\
\hline PDT & Leonel Brizola & 2.015 .836 & 3,18 \\
\hline PPR & Esperidião Amin & 1.739 .894 & 2,75 \\
\hline PR N & Carlos Gomes & 387.738 & 0,61 \\
\hline PSC & Hernani Fortuna & 238.197 & 0,38 \\
\hline \multicolumn{2}{|c|}{ Em Branco } & \multicolumn{2}{|l|}{7.192 .116} \\
\hline \multicolumn{2}{|l|}{ NuLos } & \multicolumn{2}{|l|}{7.444 .017} \\
\hline \multicolumn{2}{|c|}{ Total dosVotos Válidos } & \multicolumn{2}{|l|}{63.312 .331} \\
\hline \multicolumn{2}{|c|}{ Votos Contabilizados } & \multicolumn{2}{|l|}{77.948 .464} \\
\hline \multicolumn{2}{|c|}{ ELEITORES } & \multicolumn{2}{|l|}{94.782 .803} \\
\hline
\end{tabular}

F onte:Tribunal Superior Eleitoral.

Em 1994, os mecanismos tradicionais da política partidário- eleitoral brasileira - apelo popular direto somado a amplas e heterogêneas alianças com candidatos aos governos estaduais e ao Legislativo - voltam a descrever bem a vitória de FHC no primeiro turno, em 15 de novembro. A aliança eleitoral entre o PSD B e o PFL foi criticada por colegas tucanos, por jornalistas e por intelectuais brasileiros devido ao risco de perda de eleitores de esquerda. A té o líder da campanha de FHC em 1994 afirmou que a coligação com os pefelistas levaria eleitores tradicionais dos tucanos, nas áreas urbanas do Sudeste, a se deslocarem para o PT. M as a pers- 
pectiva aqui adotada não é a de que a dimensão ideológica determina o voto (ver Tabela 3). O s conceitos de eleições críticas e realinhamento eleitoral nos levam a sustentar que a aliança eleitoral entre o PSD B e o PFL como também os sete anos de governo de coalizão PSDB-PFL tenham criado uma nova clivagem entre governo e oposição no sistema partidá rio brasileiro.

A campanha presidencial de 1998 reforçou essa tendência do eleitora do brasileiro, no sentido de dividir-se entre a aliança governista tucana e os grupos de oposição liderados pelo PT (ver Tabela 4). As teorias sobre eleições críticas e realinhamento eleitoral sugerem que a consolidação da democracia brasileira, desde 1988, tem a ver com esse processo de mobilização das máquinas eleitorais nas disputas entre governo e oposição por grandes blocos de eleitores. A dificuldade que tiveram os candidatos dos pequenos partidos para contestar a predominância do PSD B e do PT sugere que, desconsiderando a eleição de 1989 , estes dois partidos ajudaram a criar duas grandes alianças, uma de centro-esquerda e outra de centrodireita, a partir de 1994.

TABELA 4

E leições P residenciais de 1998

\begin{tabular}{l|l|l|l}
\hline Partido & Candidato & Votos & \%VotosVálidos \\
\hline PSDB & Fernando H. Cardoso & 35.936 .540 & 53,06 \\
PT & Luiz Inácio da Silva & 21.475 .218 & 31,71 \\
PPS & Ciro Gomes & 7.426 .190 & 10,97 \\
\hline Pequenos Partidos & & 2.884 .527 & 4,25 \\
\hline Em Branco & 6.688 .403 & \\
Nulos & 8.886 .895 & \\
Total dosVotosVálidos & 67.722 .475 & \\
Votos Contabilizados & 83.297 .773 & \\
Eleito res & 106.101 .067 & \\
\hline
\end{tabular}

F onte:Tribunal Superior Eleitoral.

A vitória da aliança eleitoral PT-PL em 2002 confirma o fato de que uma aliança partidária trabalhista de centro-esquerda tenha chegado ao poder muito mais rapidamente do que no histórico comparado dos partidos socialistas e trabal histas europeus (ver Tabela 5). 
TABELA 5

E leições P residenciais de 2002

\begin{tabular}{|c|c|c|c|c|c|}
\hline \multirow[b]{2}{*}{ PARTIDOS } & \multirow[b]{2}{*}{ Candidato } & \multicolumn{2}{|c|}{$\begin{array}{c}\text { PrimeIRo } \\
\text { TURNo }(6 / 10)\end{array}$} & \multicolumn{2}{|c|}{$\begin{array}{c}\text { Segundo } \\
\text { TuRno }(27 / 10)\end{array}$} \\
\hline & & Votos & $\begin{array}{l}\text { \%VOTOS } \\
\text { VÁLIDOS }\end{array}$ & Votos & $\begin{array}{l}\text { \%VOTOS } \\
\text { VÁLIDOS }\end{array}$ \\
\hline PT-PL & Luiz Inácio Lula da Silva & 39.443 .876 & 46,4 & 52.793 .364 & 61,3 \\
\hline PSD B-PM DB & José Serra & 19.700 .470 & 23,2 & 33.370 .739 & 38,7 \\
\hline PSB & Anthony Garotinho & 15.175 .776 & 17,9 & & \\
\hline PPS-PDT-PTB & Ciro Gomes & 10.167 .650 & 12,0 & & \\
\hline Pequenos Partidos & & 440.636 & 0,5 & & \\
\hline \multicolumn{2}{|l|}{ EM BRANCO } & \multicolumn{2}{|l|}{2.873 .203} & \multicolumn{2}{|l|}{1.272 .760} \\
\hline \multicolumn{2}{|l|}{ Nulos } & \multicolumn{2}{|l|}{6.975 .128} & \multicolumn{2}{|l|}{3.772 .138} \\
\hline \multicolumn{2}{|c|}{ TOTAL DOSVOTOSVÁLIDOS } & \multicolumn{2}{|l|}{67.722 .475} & \multicolumn{2}{|l|}{86.164 .103} \\
\hline \multicolumn{2}{|c|}{ Votos Contabilizados } & \multicolumn{2}{|l|}{94.776 .749} & \multicolumn{2}{|l|}{91.209 .001} \\
\hline \multicolumn{2}{|l|}{ ELEITORES } & \multicolumn{2}{|l|}{115.254 .113} & \multicolumn{2}{|l|}{115.254 .113} \\
\hline
\end{tabular}

F onte:Tribunal Superior Eleitoral.

U ma vez que ideologia, identificação partidária e outros fatores de longo prazo não são as principais determinantes da intenção de voto no B rasil, os debates e a propaganda eleitoral na televisão surgem como fatores centrais que determinam a eleição presidencial brasileira. D ado que 0 marketing político do país já trabalhou em quatro eleições presidenciais, desde a C onstituição de 1988 (sem mencionar as eleições estaduais, municipais e legislativas), é importante considerarmos essa dimensão do processo. 0 tempo de exposição na televisão das campanhas presidenciais é importante porque a vasta mai oria dos eleitores brasileiros das classes C, D e E revela-se indecisa quanto ao voto presidencial até poucas semanas antes da eleição. Esses eleitores, os indecisos, representam aproximadamente $40 \%$ do total e parecem ser influenciados predominantemente pela tel evisão.

A volatilidade das intenções de voto em eleições presidenciais também está ligada a fatores geográficos. $N$ esse sentido, as campanhas presidenciais brasileiras são vencidas ou perdidas na disputa de grandes blocos de eleitores indecisos em estados com grande população. D os 114 milhões de eleitores brasileiros em 2002, 25,6 milhões residiam no estado de São Paulo, 12,6 milhões em M inas Gerais e 10,2 milhões no estado do R io de 
Janeiro. Em seguida vem a Bahia, com 8,5 milhões de eleitores, o $\mathrm{R}$ io G rande do Sul, com 7,3 milhões, e o Paraná, com 6,6 milhões. Embora os eleitorados de Pernambuco (5,4 milhões) e C eará (4,8 milhões) sejam consideráveis, o número de eleitores por estado cai dramaticamente no restante das demais unidades da federação. I sso significa que a grande maioria dos votos, capaz de determinar o resultado de uma eleição presidencial, deve ser obtida nesses grandes colégios eleitorais.

A dinâmica da opinião pública na avaliação do desempenho presidencial também confirma essa volatilidade de posicionamento durante as campanhas eleitorais. Embora os elevados índices positivos que predomina ram durante grande parte do primeiro mandato do presidente FHC (1994-1998) tenham decaído, as avaliações durante seu segundo mandato (1998-2002) parecem refletir um novo padrão. As pesquisas sugerem que o número de brasileiros que consideravam o desempenho do governo FHC "regular" mantinha-se relativamente constante, em cerca de $40 \%$. Por outro lado, a percentagem de brasileiros que consideravam seu desempenho "ruim" ou "bom" flutuou bastante em face dos fatos. Por exemplo, em setembro de 1998, as pesquisas do Datafol ha revelaram que apenas $17 \%$ dos brasileiros desaprovavam fortemente a gestão FHC. U m ano depois, em 1999, a reprovação aumentou para 56\%; dezoito meses depois, em setembro de 2001 , ela diminuiu para $30 \%$. A volatilidade também caracterizou as percepções positivas sobre o presidente $\mathrm{FHC}$, decaindo de $43 \%$, em setembro de 1998, para $13 \%$ um ano depois, e elevando-se novamente até atingir um pico de $26 \%$ em março de 2001 . A exemplo dos níveis de intenção de voto em campanhas presidenciais, as pesquisas revelam que as percepções do desempenho do presidente também flutuam dramaticamente.

\section{A presidência brasileira e as reformas tucanas (1999-2002)}

A pós dois mandatos de quatro anos, as reformas tucanas deixaram uma presidência substancialmente diferente. Durante a primeira gestão, FHC conseguiu aprovar uma série de emendas constitucionais que deram fim a monopólios estatais e criaram novas agências federais, com 0 objetivo de regular as empresas sob concessão. Surgiram novos merca dos e ordenamentos jurídicos em setores como os de petróleo, gás natural, telecomunicações, energia elétrica, mineração e transportes. M uitos serviços sociais foram descentralizados para os governos estaduais e 
municipais. Como já mencionado, a reforma administrativa reduziu 0 número de servidores federais, com mais de setecentos mil servidores, quando da posse de FHC, para cerca de 490 mil, em 2003. Além disso, houve uma grande modernização e aumento da agilidade das burocracias federais. A partir do momento em que uma série de crises cambiais e financeiras abalou o Brasil e as finanças internacionais durante 0 final da década de 1990, as reformas financeira e fiscal adquiriram maior importância, fazendo com que taxas de câmbio flexíveis, metas de inflação e a busca de superávits primários viessem a se tornar políticas pontuais a partir de 1999. A seguir, analisamos esse conjunto de reformas tucanas durante a segunda gestão $\mathrm{FHC}$.

A descrição de Bresser Pereira (1998) das mudanças organizacionais durante a gestão FHC como uma terceira onda de reformas administrativas define um plano histórico e comparativo, 0 qual resumimos com 0 adjetivo "tucano" . 0 M inistério da Administração e R eforma do Estado (M are) propôs, no início de 1995, uma série de metas que tinha por objetivo reformular o governo federal por meio do uso de gestão gerencial (ou seja, de métodos de gestão administrativa em empresas privadas), como também de repassar políticas aos governos estaduais e municipais com a ajuda de organizações não- governamentais e a presença de uma sociedade mais mobilizada. Essa reforma administrativa já criou uma nova geração de servidores públicos federais, selecionados por concurso e formados pela Escola $\mathrm{N}$ acional de A dministração Pública (Enap), para trabalhar cruzando ministérios e secretariados tradicionais, numa tentativa de implementar políticas em colaboração entre gabinetes e com a participação de grupos organizados da sociedade.

Essas reformas administrativas tucanas são importantes para nossa abordagem, porque foram concebidas para aumentar a capacidade da presidência em atingir metas prioritárias. D urante seu segundo mandato, $\mathrm{FHC}$ tentou conduzir esforços governamentais já presentes por meio de administradores federais que responderiam diretamente à presidência para implantar programas envolvendo diversos ministérios e agências governamentais, organizações não-governamentais e autoridades estaduais e municipais. Esse estilo de governar parece persistir na atual gestão do governo federal.

Esse núcleo do Executivo é apresentado no Q uadro 1: primeiro, os cargos mais próximos da presidência, partindo das principais secretarias do Palácio do Planalto, incluindo os cargos de interesse especial 
para as reformas tucanas; em seguida, temos os ministérios de política econômica, ministérios de política social e ministérios militares, com variação considerável de poder dependendo do momento político e da liderança do cargo.

QUADRO 1

Secretarias e M inistérios que $\mathrm{R}$ espondem diretamente ao P residente

SeCRETARIAS CENTRAIS DA PRESIDÊNCIA

Casa Civil; Secretaria Geral; Secretaria das Comunicações; C ontrolador Geral; Gabinete da Segurança Institucional; Procurador Geral; Secretário Especial de D esenvolvimento U rbano; Secretário Executivo da Comunidade Solidária; Secretário dos N egócios Estratégicos.

M INISTÉRIOS DE POLÍTICA ECONÔMICA

Fazenda; Planejamento; $O$ rçamento e G estão.

M INISTÉRIOS SETORIAIS

Indústria, C omércio eTurismo; A gricultura, A bastecimento e R eforma A grária; M inas e Energia; Transportes. M eio Ambiente; Comunicações.

M INISTÉRIOS DE POLITICA SOCIAL

Trabalho, Previdência Social e Assistência; Saúde, Educação e Esportes; C ultura.

M INISTÉRIOS POLÍTICOS

R elações Exteriores; Justiça; $M$ are.

M INISTÉRIOS MILITARES

D efesa; $M$ arinha; Exército; Força Aérea.

Fonte: www.planalto.gov.br.

Dada a separação física entre os ministérios e os cargos executivos lotados no palácio do Planalto, a presidência tende a passar autoridade às suas principais secretarias políticas, que administram as relações com 0 Legislativo, o Judiciário e os ministros. D esde 1995, as questões políticas concentraram-se na C asa C ivil e na Secretaria-geral, enquanto a Secretaria da Comunicação lida com a mídia e a imprensa, e o Procurador-geral trata de questões jurídicas. 0 Gabinete da Segurança Institucional concentra-se em questões de segurança interna, e a Secretaria de N egócios Estratégicos é responsável pelo planejamento de mais longo prazo. De 1995 a 2002, o presidente fez grande uso dos líderes partidários no Legislativo para fazer ligações entre os poderes em vez de nomear representantes para lidar com o Congresso. 


\section{Bancospúblicose gestão presidencial}

O utra dimensão das reformas tucanas está intricada com os bancos do governo federal. Embora muitos considerem os anos de 1990 um período de neoliberalismo no Brasil, a verdade é que em 2002 as três maiores instituições financeiras brasileiras ainda são públicas. A pós uma década de investimento externo e reformas financeiras concebidas para enquadrar os bancos brasileiros dentro dos limites de risco de crédito e prudência bancária (estabelecido pelo Banco Internacional de Compensações no A cordo de C apital da Basiléia II), a presidência mantém um poder de iniciativa financeira e política considerável junto aos bancos públicos federais. 0 Banco do Brasil (BB) é o principal agente de crédito e desenvolvimento rural, concentrando-se, também, em programas de comércio exterior e exportações. $\mathrm{O}$ Banco $\mathrm{N}$ acional de Desenvolvimento Econômico e Social (BN DES) oferece crédito de longo prazo a setores econômicos tidos como críticos pelo governo federal no que se refere ao desenvolvimento social e econômico. 0 BN DES também coordenou o programa federal de privatização e ofereceu recursos à exportação. $O$ Banco do $N$ ordeste (BN B) e o B anco da A mazônia (Basa) atuam em desenvolvimento regional. Finalmente, a $\mathrm{C}$ aixa E conômica Federal (CEF) dedica-se tradicionalmente ao desenvolvimento urbano, especialmente saneamento e imóveis residenciais, e à transferência de benefícios governamentais, como pensões, programas de poupança pública e FGT S, e, ainda, a programas sociais associados ao cartão do cidadão. Esse conjunto de bancos públicos é de considerável importância macroeconômica, política e social.

Em 22 de junho de 2001, o M inistro da Fazenda, Pedro M alan, anunciou um amplo programa de refinanciamento dos bancos federais públicos brasileiros. Esse programa injetou $R \$ 12,5$ bilhões nos bancos federais para que atendessem aos requisitos do A cordo de $C$ apital da Basiléia e à $R$ esolução no 2.682/ 99 do BC, que estabelecem diretrizes quanto a provisões para fazer frente ao risco de crédito. Essas diretrizes tinham por objetivo sal vaguardar a sobrevivência desses bancos como agentes, por excelência, de implementação de políticas sociais e econômicas do governo federal, ao mesmo tempo em que criavam uma proteção contra o surgimento de grandes passivos. A saber, o investimento total do BN DES quadruplicou durante os anosFH C, atingindo R $\$ 32$ bilhões em 2002, quantia maior do que os investimentos de instituições financeiras internacionais como o Banco M undial e o Fundo M onetário Internacional (FMI). 


\section{Mais reformas tucanas: tributária e orçamentária}

As reformas tucanas também incluem novos mecanismos de proposta, debate e implementação do 0 rçamento federal que visam a abrir mais o processo político orçamentário ao escrutínio público. Em 1995, a M edida Provisória no 1.550 estabeleceu novos procedimentos para o Sistema de Planejamento e 0 rçamento federal. 0 primeiro plano trienal foi proposto em 1996, ao passo que a Lei da R esponsabilidade Fiscal e a Lei do 0 rçamento A nual foram aprovadas em 2000. Essas leis estabeleceram novas regras para transformar as projeções orçamentárias dos planos plurianuais (de três a cinco anos) em metas anuais de gastos, que passaram a ter supervisão do Legislativo e do Judiciário, além de ter responsabilização penal de administradores que não cumprissem certos parâmetros orçamentários. A administração FHC também criou o SistemaTrienal de A compa nhamento 0 rçamentário, concebido para monitorar os gastos do governo e proporcionar informações às comissões dos poderes Executivo e Legislativo. Parece-nos que essa modernização e reforma do processo orçamentário avançaram contra os antigos padrões de emendas excessivas e lutas para liberar recursos. $\mathrm{N}$ esse sentido, o legado das reformas tucanas parece ser 0 de gastos governamentais federais mais próximos aos do orça mento proposto, ou a exigência de aprovação do C ongresso para que mudanças sejam feitas.

$\mathrm{O}$ utras reformas importantes durante a segunda gestão $\mathrm{FHC}$ modernizaram a captação de impostos pelo governo federal. D urante os oito anos do governo, a arrecadação cresceu $42,7 \%$ em termos reais, com a carga tributária brasileira em 2002 superando 40\% do PIB, um nível consideravelmente mais elevado do que 0 da maioria das economias emergentes, $\mathrm{e}$ semelhante à carga tradicionalmente elevada dos países europeus. R eforma tributária para a maioria dos economistas significaria a simplificação do sistema de impostos brasileiros, mas os efforços nesse sentido fracassaram durante os anos FHC por ameaçarem alterar dramaticamente os fluxos de recursos entre os níveis federal, estadual e municipal. A ssim, a modernização da arrecadação substituiu reformas abrangentes.

O caráter gradualista das relações entre os poderes pode ser visto na derrota de iniciativas mais amplas de reforma tributária. 0 presidente FHC foi mal-sucedido em três importantes tentativas de mudar os impostos desde sua posse em 1995. $N$ aquele mesmo ano, o então ministro do Planejamento, José Serra, propôs alterar o Imposto sobre C irculação 
de M ercadorias e Serviços (ICM S). M as alertas vindos das autoridades fiscais federais e a oposição feita pelos governadores impediram que o projeto se transformasse em lei. Em 1997, novas iniciativas com vistas à substituição do ICM S geraram cinco projetos no Congresso, mas nenhum deles foi aprovado. Em 1999, o Congresso tentou novamente aprovar uma lei que tinha por objetivo eliminar os impostos cumulativos e alterar o cálculo do IC M S, maso então secretário da R eceita Federal, Everardo M aciel, alertou que haveria uma queda dramática da arrecadação se as medidas fossem implementadas, gerando um novo veto no sistema. Em 1999, também foi formada uma comissão com representantes do Congresso, do M inistério da Fazenda e dos governos estaduais para criar uma agenda legislativa para a reforma tributária. E, apesar do caráter gradualista das reformas, finalmente submetidas à apreciação do C ongresso durante 0 ano de 2001 (para unificar a legislação do IC M S e eliminar o acúmulo das contribuições para o PIS-Pasep), o projeto também encalhou nas comissões do Congresso.

0 utro processo importante que diz respeito aos orçamentos federais é 0 de garantir a continuidade administrativa durante as transições de governo. $\mathrm{N}$ esse sentido, chegando ao fim da segunda gestão, FH C introduziu uma série de mecanismos para facilitar a transição de poder após as eleições de outubro de 2002.0 presidente convidou os quatro principais candidatos à presidência para uma reunião, em agosto, a fim de discutir os mecanismos de transição e esclarecer as obrigações futuras, por exemplo, nos termos do acordo com o FM I. FH C também autorizou a criação de cinqüenta cargos e a instalação de espaço físico para a equipe de transição do presidente eleito, Luiz Inácio Lula da Silva, estabelecendo também uma agenda das questões mais prementes que bateriam à porta do novo governo nos primeiros cem dias de 2003.

\section{A presidência e a nova política econômica tucana (1999-2002)}

A campanha eleitoral de 1998 ocorreu durante a crise cambial da R ússia. 0 primeiro ano da segunda gestão do $\mathrm{FHC}, 1999$, foi dominado pelo processo de desvalorização do $\mathrm{R}$ eal e a transição de um regime cambial fixo para um regime flexível. Considerando a crise de energia durante 2001 e o choque de investimento externo durante 2002, só resta o ano de 2000 como um período, durante a segunda gestão FH C, que foi relativamente sem crise ou choque econômico. Isso sugere que o tripé básico de 
políticas econômicas a partir de 1999 - rigor fiscal, metas de inflação e câmbio flexível - inaugurou um novo conjunto de políticas com grande tendência de continuidade após 2002. A qui, enfocamos al gumas características das políticas econômicas durante a segunda gestão FH C , considerada amplamente em termos dos processos econômicos, sociais e políticos desde a Constituição de 1988.

$\mathrm{N}$ esses termos gerais, o governo tucano procurou um deslocamento em relação ao tradicional modelo brasileiro do desenvolvimento encabeçado pelo Estado para um novo regime que procura basear-se na relação entre as forças do mercado e a regulação governamental. Em vez do tra dicional modelo de planejamento central e investimento dirigido por empresas estatais, o novo regime consistiria de agências reguladoras que procurassem garantir a presença de mercados competitivos. A legislação visando a esse novo regime, baseado no fim dosmonopólios e na criação de agências reguladoras, foi aprovada entre 1995 e 1998, abrangendo diversas emendas constitucionais e diversas leis complementares concebidas para concluir as privatizações e garantir a competição no mercado. Assim, foram criadas a A gência $\mathrm{N}$ acional de Energia Elétrica (A neel), a A gência $\mathrm{N}$ acional de Telecomunicações (A natel), estas para regular os setores de energia elétrica e de telecomunicações, respectivamente, e a A gência $\mathrm{N}$ acional do Petróleo (AN P), que substituiu o monopólio da Petrobrás por meio de novos mecanismos de concessão, privatizações e joint-ventures. $0 \mathrm{~s}$ leilões de concessões de exploração e extração de petróleo em áreas anteriormente reservadas à Petrobrás, realizados em junho de 1999, exemplificam essas mudanças fundamentais ainda em curso na estrutura da economia brasileira.

Essa passagem, da administração direta de monopólios estatais para a regulação de empresas privadas e mecanismos de mercado, foi concebida para reduzir os gastos federais, diminuir o custo dos serviços básicos e modernizar a infra- estrutura brasileira em setores que passaram por notá veis avanços tecnológicos nos últimos anos. Porém, os níveis de investimento estrangeiro direto caíram desde o pico de aproximadamente U $\$ \$ 33$ bilhões, em 1999, para em torno de U S\$16 bilhões, em 2002. Assim, a realidade maior das políticas econômicas durante a segunda gestão FH C foi de ajustamento a choque. Dessa forma, as três políticas econômicas centrais estabelecidas desde 1999 - taxa de câmbio flexível, metas de inflação e disciplina fiscal - sugerem que esse ajustamento tenha ocorrido principalmente por meio da desvalorização cambial. 
As reformas tucanas receberam um forte apoio da comunidade financeira internacional, especialmente em face da fuga de capital de risco e quedas de investimento internacional contínuas na esteira das crises financeiras internacionais de 2001, uma fuga que aumentou devido às percepções de risco político que temiam com a vitória de um governo do PT nas eleições de 2002. 0 acordo stand-by de U S\$15.65 bilhões, firmado em setembro de 2001 entre o Brasil e o FM I, como o acordo anterior de 1998, difere substancialmente dos acordos tradicionais por estabelecer metas de desempenho e não políticas (tradicionalmente ortodoxas) a serem adotadas. Em outras palavras, o governo brasileiro é responsável por atingir metas de superávit primário, inflação e dívida pública por intermédio das políticas que julgarem necessárias. U m outro acordo com o FM I no final de agosto de 2002 serviu para fazer a ponte entre o período de campanhas eleitorais e a transição governamental, no qual houve um enxuga mento das linhas de crédito internacionais sem precedentes e uma fuga de risco em geral.

\section{A presidência e a política externa tucana}

Desde a passagem de FHC pelo M inistério das R elações Exteriores, entre 1992 e 1993, a política externa brasileira procurou apresentar o país como uma plataforma de comércio global, aprofundar a integração regional - com o M ercado Comum do C one Sul (M ercosul) e a A mérica do Sul - e expandir as agendas dos países em desenvolvimento na $O$ rganização $\mathrm{M}$ undial do Comércio (O M C ) e nas $\mathrm{N}$ ações $\mathrm{U}$ nidas, ao mesmo tempo em que eram mantidas alianças tradicionais com os Estados $\mathrm{U}$ nidos e o hemisfério ocidental. U ma década após o Tratado de A ssunção, 0 comércio no M ercosul atingiu U S\$18 bilhões em 2000 (antes da crise econômicaA rgentina), enquanto o investimento estrangeiro nos seus países-membros chegou a U S\$135 bilhões entre 1998 e 2000. A pesar do impacto de crises econômicas na A rgentina e no U ruguai, as negociações para ampliar os acordos comerciais do M ercosul para que incluíssem tarifas externas comuns e aceitassem novos membros continuaram durante 2000 e 2001. A política externa tucana procurou expandir e aprofundar a integração regional no contexto da aproximação das negociações da Á rea de Livre C omércio das A méricas (A lca), em 2005.

A reunião de cúpula de chefes de Estado sul-americanos realizada em B raślia, em setembro 2000, aprofundou a agenda da Iniciativa de Inte- 
gração da I nfra estrutura R egional Sul-americana, definindo tanto eixos específicos de integração como comitês para a implementação de projetos. 0 s projetos de integração de infra-estrutura serão financiados sobretudo pelo setor privado, encabeçado pelo Banco M undial, pelo Banco Interamericano de D esenvolvimento (BID) e pelos governos. Em setembro de 2001 foi criada por medida provisória uma Comissão Interministerial envolvendo osministérios das R elações Exteriores, do Planejamento, das $\mathrm{M}$ inas e Energia, das C omunicações e do Transporte para implementar os projetos de infra-estrutura com vistas a integrar a A mérica do Sul nos próximos dez anos e elevar os níveis de desenvolvimento econômico e social.

As negociações comerciais também estiveram no centro das atenções da política externa brasileira de 1999 a 2002, com disputas perante a O M C com governos da U nião Européia, do C anadá e dos Estados U nidos, trazendo à baila divergências fundamentais quanto a barreiras tarifárias e não-tarifárias contra exportações agrícolas (e industriais) brasileiras, ao mesmo tempo em que foram desenvolvidas regras mais claras sobre antidumping e subsídios à exportação.

A separação cada vez maior entre os poderes também parece caracterizar a condução da política externa durante a década de 1990. Em vez do tradicional monopólio por parte da presidência e do M inistério das R elações Exteriores, as Comissões de R elações Exteriores da Câmara dos D eputados e do Senado, além de comissões temáticas, juntamente com as C omissões de C omércio Exterior - que envolvem a comunidade empresarial -, aumentaram sua presença, antes quase insignificante, o que sugere que a política externa tenha se tornado mais complexa e esteja mais dispersa entre as instituições políticas brasileiras. D e fato, foram estabelecidos nos estados brasileiros escritórios regionais do M inistério das $R$ elações Exteriores e outras iniciativas privadas aumentaram o número de agentes e de influências sobre a formulação e a implementação da política externa brasileira.

M edidas adotadas pelos Estados U nidos desde março de 2001 para aumentar as tarifas sobre o aço, expandir os subsídios agrícolas concedidos sob a F arm B ill e emendar a legislação pelo Trade P romotion A uthority, necessária para que 0 presidente Bush negociasse pactos comerciais, afetaram as políticas externas adotadas pelo governo brasileiro. Em vez de um consenso relutante quanto à inevitabilidade do acordo daAlca sob a liderança hemisférica dos Estados $\mathrm{U}$ nidos, o governo FH C recorreu aos par- 
ceiros do M ercosul, à C omunidade Européia e a países asiáticos para compensar o temor de se perder o acesso aos mercados americanos. A ssim, a persistência do protecionismo reforçou a procura de parceiros no sul e entre outros países emergentes, enquanto o governo tentou aprofundar a atuação do Brasil como plataforma global para o comércio, com exportações e importações dispersas entre cinco regiões do mundo.

\section{Conclusão}

Este estudo apresenta uma tentativa inicial de caracterizar o legado do segundo mandato presidencial de FH C de 1999 a 2002, centrando-se na separação dos poderes entre instituições políticas federais e no contexto social e econômico mais amplo da presidência brasileira. A creditamos que o Plano R eal e a estabilidade de preços a partir de 1994 possam vir a ser considerados uma conjuntura crítica para a história política brasileira. Isso, não simplesmente pelos novos contornos da política econômica, mas porque a transição política situou o Brasil perante os desafios do desenvolvimento político e da inclusão social, suspensos desde o golpe militar de 1964. Em termos gerais, desde 1995 houve uma passagem dos modelos tradicionais de substituição de importações e desenvolvimento liderado pelo Estado para um novo tipo de atuação que envolve a privatização de empresas estatais selecionadas em áreas capazes de incorporar avanços tecnológicos, a reforma da administração governamental e a redefinição dos elos entre o aparelho estatal e a sociedade, por meio de maior ação das organizações não-governamentais e da descentralização de atribuições e poder aos governos estaduais e municipais.

Esses desafios sociais, econômicos e governamentais coincidiram com a organização da vida eleitoral e partidária após o regime militar. $N$ esse sentido, a eleição de 1994 pode ser vista como uma eleição crítica, que parece ter produzido um novo alinhamento partidário e eleitoral caracterizado pelo surgimento de uma nova clivagem nacional entre o governo de coalizão tucano e uma oposição de centro-esquerda centrada no PT. U ma análise inicial das eleições nacionais de 1994, 1998 e 2002 sugere que esses novos alinhamentos, de eleitores e máquinas partidárias, deram-se, em boa parte, pelos oito anos de atuação pró e contra o governo $\mathrm{FHC} . \mathrm{O} \mathrm{s}$ mecanismos do governo presidencial de coalizão aprofundaram essa nova divisão política, por intermédio de uma série de alianças mutáveis, basea das em afinidade partidária, nomeações para cargos executivos e uma gama 
de relações entre poderes, num sistema federal complexo. Esse processo indica a existência de uma crescente separação e difusão de poder entre as instituições políticas brasileiras.

Em termos da presidência como organização, esse processo de separa ção dos poderes parece ter produzido significativo grau de especialização e profissionalização em seus quadros. $N$ ão é por acaso que os anos FH C coincidiram com a informatização do Palácio do Planalto durante a década de 1990. A ssim, as reformas tucanas incluíram a criação do Sistema Integrado de Informações 0 rganizacionais (Siorg), concebido para integrar as principais fontes de informação do governo federal.Talvez este seja um dos maiores legados das reformas tucanas: a modernização e a profissionalização dos quadros administrativos dentro da própria presidência, que passaram a se basear em informação de melhor qualidade, distribuída com maior velocidade do que a dos antigos procedimentos burocráticos que reduziam a agilidade das decisões presidenciais. Embora seja difícil separar desenvolvimentos institucionais duradouros de estilos presidenciais pessoais, parece provável que os novos sistemas de informações legislativas, judiciais e políticas, desenvolvidos para auxiliar o presidente FH C, sejam úteis no futuro, qualquer que seja o estilo pessoal adotado pelo novo presidente.

Finalmente, essa reflexão inicial sobre a segunda gestão presidencial de FH C sugere ser oportuno o alerta de 0 'D onnell (1996) sobre asilusõesda consolidação da democracia para que se proceda a uma análise empírica mais cuidadosa das novas experiências políticas após as transições de regimes autoritários no Sul e no 0 riente mundial. Lamentavelmente, a presidência brasileira ainda é muito pouco estudada nesse sentido. Em vez de repetir as trajetórias anteriores das poliarquias antigas, esta breve investigação sugere uma separação cada vez maior de poderesa partir da C onstituição federal de 1988, como também um impacto importante das reformas tucanas sobre a sociedade, a política e a economia no Brasil. N ossa abordagem, que se limitou à presidência durante a segunda gestão $\mathrm{FH} \mathrm{C}$, não pretende negar ou ocultar a brutal realidade brasileira de exclusão, mas sugerir que os desafios urgentes de inclusão social e de democratização possam ocorrer por caminhos diferentes que os experimentados anteriormente. 


\section{ReferênciasBibliográficas}

American Political Science Association - Apsa. (1950), Toward a more responsible two party system: a report of the committee on political parties. $\mathrm{N}$ ovaYork, $\mathrm{R}$ inehart. Amorim Neto, O távio \& Santos, Fabiano. (2001), "The executive connection: presidentially-defined factions and party discipline in Brazil". Party Politics, 7: 213-234.

Andrade, R egis C. (1993), "Presidencialismo e reforma institucional no Brasil". L ua N ova, 24, São Paulo, C edec.

A N D R ADE, R egis de C astro \& JACC O U D, Luciana (eds.). (1993), E strutura e organiz ação do poder executivo. Braślia, Enap, 2 vols.

Ar antes, R ogério Bastos. (1997), Judidário e política no B rasil. São Paulo, Sumaré. A R N O LD, D ouglas. (1979), C ongress and the bureaucracy. N ew H aven, Yale U niversity Press.

A r n o Ld, Peri E. (1986), M aking the managerial presidency. Princeton, Princeton U niversity Press.

Assis Br AsIL, Joaquim Francisco de. (1896), D o governo presidencial na república brasileira. Lisboa, Cia. N acional Editorial.

Azevedo, M anuel Antonio Alvares. (1894), 0 novo governo da R epública. R io de Ja neiro, Imprensa $\mathrm{N}$ acional.

B AR BeR, James D. (1985), T he presidential character. Englewood C liffs, N . J., Prentice $\mathrm{H}$ all.

B AR BO SA, Francisco de A ssis. (1960), Juscelino K ubitschek, uma revisão na política brasileira. $\mathrm{R}$ io de Janeiro, José O lympio.

B AR BOSA, R uy. (s.d.), C ontra o militarismo: campanha eleitoral de 1909 a 1910. R io de Janeiro, J. R ibeiro dos Santos.

. (1915), 0 Sr. R uy Barbosa, no Senado, responderás insinuações do Sr. Pinheiro M achado. R io de Janeiro, Typografia e Litografia Papelaria A. M árquez.

. (1919), C ampanha presidencial: 1919. Bahia, Livro C atalinas. . (1931), R uínas de um governo: o governo H ermes, as ruínas da C onstituição, a crise moral, a justiça, manifesto a nação. $R$ io de Janeiro, Editora Guanabara.

B ARTo LINI, S. \& M AIR, Peter. (1990), I dentity, competition and electoral availability. C ambridge, C ambridge U niversity Press.

B R ASIL. Presidência da R epública. (1997), G overnos da R epública. 3. ed. B rasília, Presidência da R epública, C asa C ivil, D epartamento de Administração, Biblioteca.

Bresser Pereira, Luiz C. (ed.). (1998), R eforma do Estado e administração pública gerencial. $R$ io de Janeiro, Editora FGV.

Bryce, James. (1907), T heA merican C ommonwealth. N ovaYork, M acmillan. 
BURnham, Walter D. (1970), C ritical elections and the mainsprings of A merican politics. N ovaYork, N orton.

BUR KE, John. (1992), T he institutional presidency. Baltimore, Johns H opkins U niversity Press.

C Ar do so, Fernando H enrique. (1975), A utoritarismo e democratiz ação. São Paulo, Paz eTerra.

C AREY, John M \& \& SHugART, M attew S. (1995), Ex eautive decree authority: calling out the tanks or just filling out the forms? C ambridge, $\mathrm{C}$ ambridge U niversity Press.

C Astro, M arcus Faro de. (1997), "O Supremo Tribunal Federal e a judicialização da política”. R evista B rasileira de C iências Sociais, 12 (34): 147-156, jun., São Paulo, Anpocs.

Castro Santos, M aria H . (1997), "O jogo orçamentário da U nião: relações executivo-legislativo na terra do Pork Barrel". In: Din Iz, Eli \& Azevedo, Sérgio de (eds.). R eforma do E stado e democracia no B rasil, Braślia, Editora da U niversidade de Braślia/ Enap, pp. 82-124.

Couto, Cláudio G. (1991), "A homologação das iniciativas legislativas de interesse do executivo:um aspecto central das relações entre os poderes executivo e legislativo no Brasil". C adernos C edec, 19, São Paulo.

Cummings, M iton C. (ed.). (1988), V. O . K ey Jr. and the study of A merican politics. Washington, DC, APSA.

DAHL, R obert \& LINDBLom, Charles E. (1956), Politics, economics, and welfare. N ova York,W.W. N orton.

D'A r aujo, M aria Celina Soares. (1982), 0 segundo governoVargas - 1951-1954: democracia, partidos e crise política. $R$ io de Janeiro, Zahar.

D 'Ar aujo, M aria C elina da C unha \& CAstro, C elso (eds.). (1996), E rnesto G eisel. $\mathrm{R}$ io de Janeiro, Fundação G etúlio Vargas.

DIN Iz, Eli. (1989a), "C rise, fantasia, e descrença: as eleições presidenciais de 1989". $C$ adernos de $C$ onjuntura, $21, R$ io de Janeiro, I uperj. . (1989b), "Partidos e crise política: as eleições presidenciais de 1989" . C adernos de $\mathrm{C}$ onjuntura, 20 , $\mathrm{R}$ io de Janeiro, luperj.

D o LAN , Julie. (2000), "T he president'slieutenants: President C linton's use of political and career executives to advocate presidential priorities on capital hill" . Trabalho apresentado no Annual M eeting of the A merican Political Science Association, Washington, DC, set.

Duarte, M anoel. (1918), C arlos Peixoto e seu presidencialismo. R io de Janeiro, Typ. do Jornal de Commercio.

Edwar DS, George, III. (1989), A t the margins: presidential leadership of C ongress. N ew $\mathrm{H}$ aven, $\mathrm{Yale} \mathrm{U}$ niversity Press. 
EdwAR DS, George, III et al. (eds.). (1993), R esearching the presidency. Pittsburgh, U niversity of Pittsburgh Press.

FEN N O, R ichard. (1959), T he president's cabinet. N ovaYork,V intage.

Fer ReIR A, Waldemar M artins. (1952), A federação e o presidencialismo no sistema constitucional brasileiro. São Paulo, R evista dosTribunais.

FiguelR Edo, A rgelina C.\& LIM o n GI, Fernando. (2001), Executivo e legislativo na nova ordem política. R io de Janeiro, FGV.

Green SteIn , Fred I. (1982), T he hidden hand presidency. N ovaYork, Basic B ooks.

Grossm An, M ichael \& KUMAR, M artha. (1981), Portraying the president. Baltimore, Johns H opkins $U$ niversity Press.

Guan Abar A, Alcindo. (1902), A presidência C ampos Salles: política e finanças, 18981902. R io de Janeiro, Laemmert.

H Am BLo CH, Ernest. (1981), Sua M ajestade do B rasil: um estudo do B rasil constitudional, 1889-1934. Brasília, Editora da U niversidade de Braślia.

H ART, John. (1987), T he presidential branch. N ovaYork, Pergamon.

H ART, R oderick. (1987), T he sound of leadership. C hicago, U niversity of C hicago Press. H EsS, Stephen. (1976), 0 rganiz ing the presidency.Washington, D C , B rookings Institution. H OOGENBOOM, Ari. (1968), 0 utlawing the spoils: a history of the divil service reform movement, 1865-1883. U rbana, U niversity of Illinois Press.

I N GR AHAM , PatriciaW. (1995), T he foundation of merit: public service in A merican democracy. Baltimore, Johns H opkins U niversity Press.

JOHNSON, Loch. (1984), The making of international agreements: congress confronts the exeautive. N ovaYork, $N$ ew York U niversity Press.

Jo nes, C harles O . (1994), T he presidency in a separated system.Washington, DC, B rookings Institution.

JOR GE,V Vladimyr L. (1995), A eleição presidencial de 1994 e os meios de comunicação de massa. D issertação de mestrado, $R$ io de Janeiro, luperj.

KEY,V. O. (1950), "A theory of critical elections”. Journal of Politics, 17: 3- 18. . (1963), T he responsible electorate: rationality in presidential voting, 1930-1960. N ovaYork, Basic Books.

Ker n elL, Samuel. (1978), “Explaining presidential popularity” . A merican Political Science R eview, 72: 506-522, jun.

. (1984), "T he presidency and the people: the modern paradox". In: N ELSON,

M. (ed.). T he presidency and the political system, Washington, DC, C Q Press.

K IN DER , D onald. (1981), "Presidents, prosperity, and public opinion". Public 0 pinion Q uarterly, 45: 1-21.

KIN G, Gary. (1993). "T he methodology of presidential research". In: EdwARDS, G. et al. (eds.). R esearching the presidency, Pittsburgh, U niversity of Pittsburgh Press. 
LAm o Unier, Bolivar. (1994), "Brazil: towards parliamentarism?" In: Linz, Juan \& Valenzuela, Arturo (eds.).T he failure of presidential democracy in Latin A merica, Baltimore, Johns H opkins U niversity Press, pp. 179-219.

Lam o un ner, Bolivar et al. (1990), C em anos de eleições presidenciais. São Paulo, Idesp. LAN ZARo, Jorge. (ed.). (2001), T ipos de presidencialismo e coaliciones políticas en A mérica $L$ atina. Buenos A ires, Clacso.

LIGHT , Paul. (1991), T he president's agenda: domestic policy choice from K ennedy to R eagan.

Baltimore, Johns H opkins U niversity Press (edição revista).

Lin d BLo M , C harles. (1968), T he policy-making process. Englewood C liffs, N J, Prentice$\mathrm{H}$ all.

LIN Z, Juan \& StEPAN , Alfred. (1996), P roblems of democratic transition and consolidation. Baltimore, Johns H opkins U niversity Press.

LIN Z, Juan \& V ALEn zU ELA, A rturo (eds.). (1994), T he failure of presidential democracy in $\mathrm{L}$ atin $\mathrm{A}$ merica. Baltimore, Johns $\mathrm{H}$ opkins $\mathrm{U}$ niversity Press.

LIPSET, S. M . \& R OKKAN, S. (eds.). (1967), Party systems and voter alignments. N ova York, Free Press.

Lo Ureiro, M aria R ita \& A bru cıo, Fernando Luiz. (1998), "G abinetes presidenciais e provimento do alto escalão burocrático: 0 caso do ministério da Fazenda na experiência brasileira". Trabalho apresentado no $22^{\circ}$ Encontro daA npocs, C axambu (mimeo).

Low I,T heodore. (1979), T he end of liberalism: the Second R epublic of the U nited States. N ovaYork, N orton.

. (1985), T he personal president. Ithaca, C ornell U niversity Press.

Lu st o SA, I sabel. (1989), H istória de presidentes: a R epública no C atete. Petrópolis,Vozes. M ACKENZIE, G. C alvin. (1981), T he politics of presidential appointments. N ovaYork, Free Press M ain WAR IN G, Scott \& Shugart, M atthew (eds.). (1997), P residentialism and democracy in L atin A merica. Cambridge, C ambridge U niversity Press.

M ARGOLIS, Lawrence. (1986), Executives agreements and presidential power in foreign policy. N ovaYork, Praeger.

M Ath EW, David. (1989), D ivided we govern. N ew H aven, Yale U niversity Press.

M en des, Antonio M.T.\& Venturı, Gustavo. (1994), “Eleição presidencial: o Plano R eal na sucessão de Itamar Franco" . 0 pinião Pública, 2 (2), C ampinas, C esop.

Meneguello, R achel. (1996), "Electoral behavior in Brazil:The 1994 presidential elections". International Social Science Journal, 146, 0 xford, B lackwell.

M etten heim , K urt von. (1995), T he B razilian voter: mass politics in democratic transition, 1974-1986. Pittsburgh, U niversity of Pittsburgh Press.

(ed.). (1997), Presidential institutions and democratic politics: comparing regional contexts. Baltimore, Johns H opkins U niversity Press. 
Metten heim , Kurt von \& M Alloy, James (eds.). (1998), D eepening democracy in L atin A merica. Pittsburgh, U niversity of Pittsburgh Press.

M ueller , John. (1970), "Presidential popularity from Truman to Johnson”. A merican Political Science R eview, 64: 18-34.

N ATHAN , R ichard. (1983), T he administrative presidency. N ovaYork, W iley.

N EUStAdt, R ichard. (1960), Presidential power. N ovaYork, W iley.

N O R R AN DER , Barbara. (1992), SuperTuesday. Lexington, U niversity Press of Kentucky. O 'D O N N ELL, G uillermo. (1996), "Illusions about consolidation”. J Jurnal of D emocracy, 7(2): 34-51.

O STROGORSKI, M. I. (1964), D emocracy and the organization of political parties in the U nited States and G reat B ritain. G arden C ity, D oubleday.

O stron ,C harles \& Jo B, B rian. (1986), "T he president's use of force”. A merican Political Science R eview, 80: 541-566, jun.

O ST RON , C harles \& SIM O N , D ennis. (1985), "Promise and performance: a dynamic model of presidential popularity". A merican Political Science R eview, 79: 334358, jun.

Paler m o,Vicente. (2000), "C omo se governa o Brasil? 0 debate sobre instituições políticas e gestão de governo". D ados, 43 (3): 521-557, R io de Janeiro, I uperj.

Pessan ha, C harles. (1997), R elações entre os poderes executivo elegislativo no B rasil: 1946 1994. Tese de doutorado, São Paulo, Faculdade de Filosofia, Letras e Ciências H umanas da U niversidade de São Paulo.

Pesso a, E pitácio. (1955), 0 bras completas de E pitácio Pessoa. R io de Janeiro, Instituto N acional do Livro, vol. 1.

PIER SON , Paul \& SKO CPOL,T heda. (2003), " $\mathrm{H}$ istorical institutionalism in contemporary political science". In: KATZN ELSON , I ra \& M ILNER , H elen (eds.). Political science: the state of the discipline, N ovaYork,W.W. N orton/ APSA, pp. 693-721.

R AGSDALE, Lyn. (1984), "T he politics of presidential speechmaking”. A merican Political Science R eview, 78: 971-984, dez. _. (1993), P residential politcs. Boston, H oughton M ifflin.

R O M ER O, Silvio. (1978), Parlamentarismo e presidencialismo na R epública brasileira: cartas ao conselheiro R uy B arbosa. Brasília, Editora da U nB.

R U BIN , R ichard. (1981), Press, party, and presidency. N ovaYork, N orton.

SAdEk, M ariaTereza (org.). (1999), 0 sistema de justiça. São Paulo, Sumaré.

SAlles, M anuel Ferras de C ampo. (1983), D a propaganda à presidência. Brasília, Editora da U niversidade de Braślia.

SARTO R I, Giovanni. (1982), Partidos políticos e sistemas partidários. Braślia, Editora da U niversidade de Brasília.

SCHLESIn GER JR ., A rthur, (1973), T he imperial presidency. Boston, H oughton M ifflin. 
Schultz, David A. \& M ARAnto, R oberto. (1998), The politics of aivil service reform. $\mathrm{N}$ ovaYork, Peter Land.

ScIglian O, R obert. (1971), T he Supreme C ourt and the presidency. N ovaYork, Free Press. SIGELMAN , Lee \& KNIGHT , K athleen. (1983), "W hy does presidential popularity decline? A test of the expectation/ disillusion theory". Public 0 pinion $Q$ uarterly, 47: 310-324.

Si Lva, Suely B. de. (1989), 0 s presidentes da R epública: guia dos acervos privados. R io de Janeiro, CPD O C/FGV.

Skowron Ek, Stephen. (1982), B uilding a N ew A merican State: the expansion of national administrative capacities, 1877-1920. N ovaYork, C ambridge U niversity Press.

So uzA, M aria do Carmo C ampello de. (1976), E stado e partidos políticos no B rasil. São Paulo, A lfa 0 mega.

Stewart, C harles H. III. (1989), B udget reform politics: the design of the appropriations process in the $\mathrm{H}$ ouse of R epresentatives, 1865-1921. N ovaYork, C ambridge U niversity Press.

St IM 50 N , James. (1976), "Public support for American presidents: a cyclical model”. Public 0 pinion Q uarterly, 40: 1-21.

T SIBELIS, George. (1997), "Processo decisório em sistemas políticos: veto players no presidencialismo, parlamentarismo, multicameralismo, e pluripartidarismo". R evista B rasileira de C iências Sociais, 12 (34): 89-117, São Paulo, Anpocs.

V AR GAS, G etúlio. (1996), D iário. R io de Janeiro, E ditora da Fundação G etúlio Vargas, 2 vols.

VAsc o n C Elo s, M arcelo J. C . (2001), D ecretos presidenciais e democrada: B rasil eA rgentina em perspectiva comparada. D issertação de mestrado, B rasília, U niversidade de Brasília, D epartamento de R elações Internacionais.

V IAN N A, Luiz Werneck et al. (1999), A judidaliz ação da política e das relações sociais no $B$ rasil. $R$ io de Janeiro, $R$ evan.

W ATSO N , Stephen et al. (1979), "A dvising the president on enrolled legislation: patterns of executive influence". Political Science Q uarterly, 94: 303-317.

W eber, M ax. (1946), “Politicsas aVocation”. In: Gerth, H ans \& M ILls, C.W. (eds.). F rom M ax W eber: essays in sodiology, $\mathrm{N}$ ovaYork, $\mathrm{O}$ xford $\mathrm{U}$ niversity Press.

W EST,W illiam \& C O O PER , Joseph. (1985), “T he rise of administrative C learance.” In: EdWAR Ds, G. et al. (eds.). T he presidency and public policy making, Pittsburgh, U niversity of Pittsburgh Press. 


\section{Resumo}

Este trabalho discute as relações entre a presidência brasileira e os outros poderes da U nião durante a segunda gestão FH C de 1999 a 2002. A hipótese central é de que a crescente separação dospoderes, apontada por vários autores desde a C onstituição de 1988, também caracteriza processos importantes ocorridos durante essa gestão de FHC. A rgumentamos que esse processo em pírico exige uma reavaliação de conceitos sobre a democracia brasileira e que teorias "separacionistas" de poder e governo oferecem novas perspectivas para o estudo das instituições políticas brasileiras. Palavras-chave: Separação dos poderes; Instituições políticas; D emocracia.

\section{Abstract}

This paper discusses the relationship between the Brazilian Presidency and other U nion powers during Fernando Henrique Cardoso's second term in office, from 1999 to 2002.T he central hypotheses is that the growing separation of powers, highlighted by various researchers since the 1988 C onstitution, also characterizesimportant processes, which took place during this time. It is argued that this empirical process demands a reevaluation of concepts on Brazilian democracy and that theories that separate power and government offer new perspectives for the study of B razilian political institutions.

Key words: Separation of powers; Political institutions; D emocracy.

Kurt von M ettenheim é university lecturer in Brazilian Studies na U niversidade de $0 x$ ford e professor-adjunto (licenciado) de sociologia política, da Escola de A dministração de Empresas de São Paulo - Fundação Getúlio Vargas (E aespFGV). 